\title{
O Carteado Científico e a Governança pela Norma: Uma Análise Antropológica sobre os Procedimentos de Avaliação da Produção Científica e da Ética em Pesquisa no Brasil ${ }^{1}$
}

\section{The Scientific Pack of Cards and Governing by Standards: An Anthropological Analysis of the Procedures for Evaluation of Scientific Production and Ethics on Research in Brazil}

\section{Hully Guedes Falcão}

Programa de Pós-graduação em Informação e Comunicação em Saúde, Fundação Oswaldo Cruz, Rio de Janeiro, RJ, Brasil

\section{Fabio Reis Mota}

Programa de Pós-graduação em Antropologia, Universidade Federal Fluminense, Niterói, Rio de Janeiro, Brasil

\section{Gabriela de Lima Cuervo}

Secretaria de Educação do Rio de Janeiro, Rio de Janeiro, RJ, Brasil

\section{RESUMO}

O objetivo deste trabalho é trazer uma reflexão sobre as reconfigurações do modelo de governança pela norma cientifica no Brasil e como elas repercutiram em novas modalidades de controle engendradas nas últimas décadas. Nossas análises resultam de pesquisa etnográfica realizada no âmbito de duas esferas avaliativas: na avaliação da produção científica e na avaliação da ética em pesquisa, espaços que são produtos de

1 Este artigo é resultado de pesquisas provenientes de recursos do Projeto Capes PRINT International Research Network on Conflict Management in Plural Public Spaces: Inequalities, Justice and Citizenship in a Comparative Perspective e do Programme Directeurs d'Études Associés (DEA) de la Fondation Maison des sciences de l'homme, Paris-França coordenados por Fabio Reis Mota, Bolsa Faperj Nota 10 concedida à Hully Falcão, e da Capes através de bolsa de doutorado destinada à Gabriela Cuervo. 
regulações que seguem um movimento internacional de estandardização, cuja tônica é a universalização de determinados protocolos e práticas. Desse modo, nossa intenção é tornar evidente sob quais standards essas diferentes regulações se baseiam, quais críticas e justificações são produzidas por seus integrantes, e como o controle, a partir do Estado, reverbera na prática científica. A premissa destes modelos padronizadores é de tornar o processo avaliativo objetivo, no entanto, à medida que os atores performam e acionam competentemente esses dispositivos, constroem representações e estratégias assentadas, muitas vezes, em suas trajetórias acadêmicas e científicas. Por fim, problematizamos o modo como esses modelos de certificação, qualificação e classificação ganham novos contornos em um mundo no qual as regras e normas são operacionalizadas de forma particularizada e por meio de critérios regidos por uma racionalidade cismática.

Palavras-chave: Governança pela norma, Avaliação, Padronização, Prática científica.

\section{ABSTRACT}

The aim of this paper is to reflect on the reconfigurations of the governing by standards in Brazil's scientific field and how they have had repercussions in new modalities of control engendered in recent decades. Our analyses result from ethnographic research carried out in two evaluative spheres: scientific production evaluation and the evaluation of ethics in research, spaces that are products of regulations that follow an international movement of standardization, whose keynote is the universalization of certain protocols and practices. Thus, our intention is to make evident under which standards these different regulations are based, which criticisms and justifications are produced by their members, and how the control, from the State, reverberates in scientific practice. The premise of these standardizing models is to make the evaluative process objective, however, as the actors perform and activate these devices competently, they build representations and strategies based, many times, on their academic and scientific trajectories. Finally, we problematize how these models of certification, qualification and classification gain new contours in a world in which rules and norms are operationalized in a particularized way and through criteria governed by a schismatic rationality.

Keywords: Governing by standards, Evaluation, Standardization, Scientific practice.

\section{INTRODUÇÃO}

Reluziu na contemporaneidade dos países “ocidentais" uma linguagem política e moral fortemente associada às práticas de normalização e estandardização das coisas, pessoas e dos 
mundos nos quais esses diferentes agentes habitam. Foucault $(1972,1987)$ observou que os mecanismos de controle das sociedades capitalistas modernas se delineavam pelas feições dos regimes de normalização e internalização das condutas e docilização dos corpos. Essa "nova alma do capitalismo" conferiu vida ao individualismo tal como o conhecemos e concedeu corpo à conformação de um sentido de ética universal fundamentada em princípios e valores próprios do liberalismo econômico e político proveniente dos países da Europa e do norte da América. Em grande medida, os EUA figuraram como a fonte irradiadora dos modelos de gestão da pesquisa, da ética na pesquisa e dos modos de governar a produção e consagração do conhecimento científico.

Uma das principais repercussões deste modelo liberal de matriz normalizadora no domínio da regulação da pesquisa - que seguia as formas do que Foucault descreveu sobre espaços disciplinares e normalizadores (tais como a prisão, os manicômios, os hospitais etc.) - foi a elaboração de critérios, princípios éticos e normativos assentados na conformação de mundos pasteurizados e que se pretendem comuns e universais. Esse processo veio se somar ao advento, nos dias atuais, do modelo de governança pela norma ${ }^{2}$ ou por standards (THÉVENOT, 1997; 2019), cujos alicerces são comuns ao da normalização ainda que mobilizado e efetuado sob o escrutínio de novas gramáticas políticas. Por caminhos distintos ao de Foucault, Thévenot (1997, p. 6) elabora algumas considerações sobre esse "liberalismo normalizador", que

[...] para além dos limites da arena mercantil, instaura uma qualificação pelo reconhecimento na opinião que não se encontra inscrita na ordem mercantil. Elencada na sua lógica própria, esta qualificação não é verdadeiramente aberta a uma prova de concorrência e tende verdadeiramente a uma uniformização que de fato prejudica a variedade no mercado de produtos. É uma tal uniformização que é procurada pelo processo de "massificação" e, atualmente, da "macdonalização". Nas tipologias das normas, esta estandardização de fato se opõe às estandardizações de lei, apelando aos regulamentos [...]. Este tipo de normalização contratual ocupa um lugar central na internacionalização dos mercados e na construção europeia. A autoridade de Estado no policiamento das mercadorias, em parte, se reporta a um dispositivo contratual governado pelas normas de qualidade. Em resultado, um composto de liberalismo e de normalização metrológica. A fórmula mesmo deste "liberalismo normalizador" indica que ele contém fortes tensões internas. Opacado pela cobertura técnica, este movimento tem grande abrangência. Ele modifica a maneira de conceber os objetos técnicos na sua valoração econômica, recompõe as figuras clássicas do produtor e do consumidor, alterando até mesmo as concepções políticas de cidadania, os modos de intervenção e as formas adequadas de governança (THÉVENOT, 1997, p. 6, tradução nossa).

2 No decorrer do texto, as categorias analíticas estarão em itálico e as categorias nativas entre aspas. 
A governança pela norma está fortemente associada aos mecanismos de certificação dos recursos renováveis, das cidades, dos bens de consumo, da política ordinária e da vida científica, bem como outros domínios da vida social. Esses movimentos normalizadores podem, por exemplo, ser observados nas plataformas digitais que submetem seus usuários a critérios e regras comuns a todos, independentemente de sua origem nacional ou cultural. A utilização de aplicativos como Uber ou iFood implica na padronização, previsibilidade e protocolos que visam uniformizar o modo como usuários e prestadores utilizam desses serviços, que independe das condições socioculturais, e transcendem as fronteirais administrativas e formais dos Estados nacionais. Fomenta-se, com isso, uma microfísica da norma, na qual as diversas dimensões da vida social são invadidas por esses princípios normativos que tendem a padronizar, estabelecer garantias, universalizar as regras e práticas representadas como comuns a qualquer cidadão do mundo. Padronizam-se as condutas e pasteuriza-se a ética.

Tal como em outros campos da vida humana, a produção científica tem sido igualmente atingida por esses processos, o da governança pela norma, pela estandardização (THÉVENOT, 1997 e 2019) e pela microfisica da norma. Nesse sentido, a Ciência hoje tem sido regida por critérios de avaliação, valoração e eticidade de natureza transnacional. A governança pela norma cientifica, desse ponto de vista, supõe promover o "espírito das normas" através da propulsão de princípios universalizantes. As boas práticas científicas, veiculadas pelos manuais das agências internacionais de fomento à pesquisa, são bons exemplos da introdução às novas gramáticas políticas e morais. Esses processos repercutem de maneira variada no mundo científico e na prática científica: no controle da ética da prática da pesquisa, nos modelos de avaliação e impacto do conhecimento científico, na emergência de plataformas digitais (como a Plataforma Lattes, a Plataforma Sucupira etc.), nas métricas que definem os Qualis das revistas, dentre outros. Nesses termos, a governança da ciência passa pelos laboratórios, revistas científicas, congressos, dentre outros espaços de produção e reprodução do conhecimento, mas igualmente é informada por formas de controle das práticas científicas que as qualificam (ou as desqualificam) a partir de critérios de julgamentos que não se desenvolvem num vazio de sentidos, significados, moralidades e da política. Pelo contrário, revela a complexa economia política desenvolvida nos sistemas de prestação e contraprestação presentes nas dinâmicas de produção da Ciência.

Todavia, as particularidades de cada campo do conhecimento, e os modos como as Ciências se desenvolvem nos contextos nacionais e culturais, são apagadas diante dessa política de universalização e pasteurização das normas científicas. As diferenças expressas no interior das normas locais, ou das suas sensibilidades jurídicas (GEERTZ, 2013), assim como as existentes nas práticas e epistemologias, são dirimidas face à primazia dos grandes esquemas normativos 
da governança científica.

Neste artigo, buscamos dar conta de uma rede heterogênea de elementos humanos e não humanos conectados e agenciados (FREIRE, 2006; LATOUR, 2001), que regulam a arena cientifica informados pelo regime de governança pelas normas, a partir de nossas etnografias sobre os critérios de avaliação do conhecimento científico e dos princípios reguladores da ética em pesquisa. Nosso material etnográfico apresenta uma gama de leituras e modos de operacionalização, convencionais ou criativos quanto ao uso das normas, associadas ao conjunto de moralidades observáveis em diferentes práticas de pesquisa e em distintas maneiras de avaliá-la no interior das agências de fomento e/ou das instituições devotadas à regulação da ética em pesquisa. É a partir destes diferentes quadros morais (BOLTANSKI; THÉVENOT, 1991) que críticas e justificações são produzidas e mobilizadas por pessoas que integram estes espaços avaliativos, sendo possível apreender criativamente os exercícios de classificação e (des)qualificação daquilo que seria percebido como justo e científico.

Compreendemos que a governança pela norma está intimamente relacionada às transformações do capitalismo e suas formas de gerenciamento do trabalho diante do novo espírito do capitalismo que se anuncia (BOLTANSKI; CHIAPELLO, 2009). Desse modo, este artigo está organizado em duas seções. Na primeira, descrevemos o modelo brasileiro de avaliação das pós-graduações no Brasil e o movimento unificador desse sistema através da reformulação institucional da Coordenação de Aperfeiçoamento de Pessoal de Nível Superior (Capes) para, então, lançar luz sobre como os atores manejam bases de dados para produzir qualificações de outros e de si mesmos. Na segunda, narramos e descrevemos os protocolos e normas que deram origem ao que hoje é chamado de sistema CEP/CONEP (Comissão Nacional de Ética em Pesquisa), principalmente a partir da análise das resoluções em uso, entrevistas e etnografia de dois Comitês de Ética em Pesquisa (CEP) da área de Ciências Humanas e Sociais. Após essa contextualização, exploramos de que modo a Plataforma Brasil ${ }^{3}$ é compreendida e performada por pesquisadores e membros desses comitês, com o objetivo de analisar as múltiplas gramáticas morais sobre as quais a governança da ética em pesquisa se baseia. Portanto, este trabalho coloca em perspectiva as práticas e os movimentos de pesquisadores no contexto de avaliação científica, visando lançar luz sobre esses processos de emergência da governança pela norma e pela microfísica da norma.

3 A Plataforma Brasil é uma plataforma digital na qual os projetos de pesquisa que tem como objeto de estudo os seres humanos são submetidos para serem avaliados pelo Sistema CEP/CONEP. O pressuposto dessa plataforma é a transparência, a partir da inclusão de documentos em meio digital a sociedade teria o acesso aos dados públicos das pesquisas aprovadas. A Plataforma Brasil é gerida pelo DataSUS - Departamento de informática e programação do Sistema Único de Saúde (SUS). 


\section{A REFORMULAÇÃo DA AVALIAÇÃo DA PÓS-GRADUAÇÃo NO BRASIL, A INTRODUÇÃO DE NOVOS INDICADORES DE PRODUTIVIDADE E O MOVIMENTO PADRONIZADOR DA CARREIRA CIENTÍFICA ${ }^{4}$}

O estabelecimento de uma atividade de pesquisa permanente no Brasil e a conformação de uma rede de cientistas são produtos do esforço de alguns agentes pela institucionalização da atividade científica, que envolveu dois movimentos principais: 1) uma associação deliberada e crescente do ensino universitário com a atividade científica; 2) a estruturação de um sistema nacional de pós-graduações e, com ela, a formulação de mecanismos cada vez mais refinados de qualificação e classificação da produção científica dos docentes e discentes desses cursos. $\mathrm{O}$ esforço centralizador do Estado na conformação de uma atividade regular de pesquisa no país passa, necessariamente, pela atuação de duas principais agências: a CAPES e o CNPq, ambas criadas em 1951. A centralidade dessas instituições na consolidação de um sistema que estreitou cada vez mais a relação entre avaliação e fomento torna-se, assim, um elemento normalizador do trabalho e da carreira científica, legitimando determinadas moralidades, práticas e éticas (ARRUDA, 1999).

Na segunda metade da década de 1990, diante da expressiva expansão dos programas de pós-graduação, houve um movimento por parte do corpo técnico e de pesquisadores atuantes na Capes para aumentar a exigência da avaliação das pós-graduações. A principal justificativa exposta em documentos da agência de fomento foi a de que a sistemática de avaliação até então adotada apresentava "sinais de esgotamento" (MARTINS, 2003, p. 13), e isso se refletia na incapacidade do modelo de discriminar a qualidade acadêmica entre os programas, a qual, de acordo com o autor, podia ser exemplificada na avaliação de 1996, quando “[...] 79\% dos cursos de mestrado e 90\% dos de doutorado obtiveram conceito 'A' ou 'B'”. De 1976 a 1997, a avaliação era expressa através de conceitos: A (muito bom), B (bom), C (regular), D (fraco) e E

\footnotetext{
4 Esta etnografia foi realizada entre 2016 e 2018, tendo como foco de análise um estrato específico de pesquisadores inseridos no circuito das bolsas premiadoras de produtividade, a saber, uma rede de pesquisadores fluminenses atuantes em coordenações de área de agências de fomento como o FAPERJ, a CAPES e o CNPq. O material de pesquisa é constituído pela articulação da análise de discursos proferidos em situação de entrevista, com um exame cuidadoso de critérios e recomendações avaliativas documentadas e publicadas na internet pelas agências de fomento, como os critérios por área de avaliação da Bolsa Produtividade do CNPq, os documentos de área da Capes e o edital Cientista do Nosso Estado, da FAPERJ.
} 
(insuficiente). A partir de 1997, passou a vigorar a classificação numérica (1 a 7), determinando-se que fossem adotados pelos comitês "padrões internacionais" na avaliação dos programas considerados "de excelência". Sendo assim, os cursos classificados com as escalas 6 e 7 seriam aqueles que demonstrassem "inserção internacional” (CUERVO, 2019).

Outro aspecto que caracterizou esse movimento de transformação no modelo de avaliação da Capes foi a parametrização ainda maior da mensuração da qualidade dos cursos de pós-graduação, que se refletiu na padronização da ficha de avaliação. Todas as áreas deveriam avaliar exatamente os mesmos quesitos, ainda que através de indicadores diferentes, adaptados a cada comitê de avaliação. Tal esforço de padronização foi ainda mais reforçado quando, nesse mesmo período, os resultados da avaliação dos cursos pelos respectivos comitês de área ${ }^{5}$ passaram a ser coordenados, acompanhados e referendados pelo Conselho Técnico-Científico de Educação Superior (CTC-ES) ${ }^{6}$ da Capes (até 1996, os conceitos finais eram de competência exclusiva dos comitês), em um movimento de centralização burocrática cada vez maior das decisões finais com relação ao credenciamento/descredenciamento de cursos, assim como das notas atribuídas pelos comitês de área (ARRUDA, 1999).

Na esteira da introdução deste modelo de avaliação dos cursos de pós-graduação, no fim da década de 1990, se discutia a necessidade de um mecanismo de qualificação da produção bibliográfica dos docentes e discentes desses programas, que neste período já era expressiva e numerosa. Até então, a avaliação do quesito produção bibliográfica era quantificadora e, diante do objetivo da agência em estimular a inserção internacional da pós-graduação brasileira e reformular a sua avaliação tomando como parâmetro o padrão europeu e norte-americano de produção científica (BARATA, 2016), a opção adotada foi criar um sistema de classificação dos periódicos, tendo como um de seus principais critérios de qualificação a circulação internacional e o seu impacto entre os cientistas. Nascia, então, o Qualis Periódicos, criado para auxiliar os comitês de área na qualificação da produção bibliográfica dos programas de pós-graduação.

Atualmente, a classificação dos periódicos é revista anualmente e, desde 2007, após uma reformulação do sistema, é estratificada em sete níveis: A1, A2, B1, B2, B3, B4 e B5, ha-

5 A Capes dispõe de 49 comitês de área que são integrados por pesquisadores que cumprem mandatos periódicos, sendo nomeados pela presidência da instituição a partir de indicações de cientistas com reconhecimento entre seus pares. Esses integrantes são responsáveis pela avaliação e classificação dos cursos de pós-graduação, além de propor e deliberar políticas específicas para suas áreas de conhecimento.

6 O CTC-ES é um órgão colegiado da Capes que tem como atribuições propor, debater e deliberar acerca de políticas e diretrizes avaliativas da agência, sendo sua responsabilidade a deliberação final acerca do credenciamento e descredenciamento de cursos de pós-graduação e os conceitos atribuídos aos programas de pós-graduação pelos comitês de área. Disponível em: https://www.gov.br/capes/pt-br/acesso-a-informacao/institucional/conselho-tecnico-cientifico-da-educacao-superior-1/competencias. Acesso em: 14 jul. 2021. 
vendo ainda o nível $\mathrm{C}$, destinado aos periódicos que não atendem aos "[...] critérios mínimos estabelecidos em cada área para ser classificado" (BARATA, 2016, p. 4). Cada comitê de área tem relativa autonomia para classificar os periódicos nos quais docentes e discentes dos programas avaliados publicam, sendo possível (e comum) que o mesmo periódico possa receber diferentes avaliações por áreas distintas.

Ao entrevistar pesquisadores que atuam ou atuaram em comitês de área da Capes, foi possível compreender algumas formas de como esses atores concebem e manejam criativamente a classificação do Qualis para fins diversos. É uma prática recorrente, por exemplo, algumas áreas rebaixarem a classificação de um periódico de área diferente - por mais que ele cumpra os critérios para uma boa classificação, de acordo com os parâmetros gerais da Capes e da própria área - para aumentar o destaque dos periódicos do próprio campo de conhecimento. Esse processo pode ser observado na fala de uma pesquisadora da área da Física:

$\mathrm{Na}$ Física, a gente, pra considerar um professor pro programa de pós-graduação pra ser avaliado como pesquisador, a gente tem que publicar de B1 pra cima. Nossas revistas são rotuladas nos As, nos estratos da Capes, basicamente em função do fator de impacto da revista. Então, é uma coisa assim, muito mais fácil pra gente rotular isso. [...] A gente tem nossas revistas da Física. Aí tem as revistas médicas. Aí tem um cara da Física que publicou nessa revista. Como ela não é da nossa área, a gente nunca põe essa revista como A1 da nossa área. Ela é rebaixada pra um A2. Se ela tem um impacto muito alto, mas não é da Física, ela ganha um A2.

A maneira como você calcula esse parâmetro de impacto tem muito a ver com a leitura da área, se é uma área pequena que lê aquela revista. O que a gente faz? Pra incentivar as pessoas a fazer instrumentação, porque é importante pra Física, a gente põe essas revistas um pouco pra cima. Um parâmetro de impacto que seria um B5, a gente bota pra um B3. Então, a gente tem um jogo, não é um trabalho tão mecânico assim não, a gente incentiva determinadas áreas. Tem áreas que publicam menos do que outras. (Bárbara, 2017, grifo nosso).

Em sua fala, a pesquisadora apresenta as estratégias do comitê da Física para "contornar" um parâmetro avaliativo considerado central para a Capes e, especialmente, para as ditas "ciências duras", que é o fator de impacto (FI). O fator de impacto é a principal métrica utilizada para avaliar as revistas científicas, cujo critério é a contabilização do número de citações que essas publicações recebem. Dentro da lógica de avaliação adotada pela Capes desde 1998 - de adequar os cursos de pós-graduação a "modelos internacionais" através de um movimento padronizador -, o fator de impacto seria representativo, dentre outros aspectos, da inserção e prestígio internacional daquele periódico. Ao mesmo tempo que nossa interlocutora considera 
"simples" rotular as revistas de sua área, pois ela se adéqua, no geral, ao cálculo do fator de impacto, ela apresenta outras práticas empregadas pelo comitê para atingir os objetivos considerados importantes para o campo de conhecimento e demonstra o aspecto flexível e complexo que este trabalho de estratificação de periódicos pode tomar.

É importante destacar que a classificação do Qualis Periódicos é também largamente utilizada pelos comitês assessores do CNPq e das fundações de amparo à pesquisa estaduais nas avaliações individuais de pesquisadores para concessão de bolsas e auxílios à pesquisa. Um dos critérios de julgamento centrais para quase todas as áreas na avaliação da Bolsa Produtividade do CNPq, incluindo as Ciências Humanas e Sociais, é a quantidade de artigos dos candidatos combinada com a classificação do Qualis Capes dos periódicos em que foram publicados. Essa "combinação" ou "empréstimo" de critérios avaliativos entre a Capes e o CNPq atesta a centralidade dessas instituições na regulação e normalização de lógicas de carreira a serem adotadas pelos pesquisadores, através de cobranças que moldam suas práticas científicas e seus ethos profissionais. Enquanto a Capes se firmou enquanto agência reguladora da avaliação da pós-graduação através da estruturação de um processo de avaliação centralizado na produção coletiva desses programas, o CNPq se firmou como agência parametrizadora das competências individuais dos pesquisadores, regulando através da distribuição de auxílios à pesquisa e bolsas que premiam a produtividade suas práticas e suas projeções de si enquanto profissionais.

\section{BASES DE DADOS E TECNOLOGIAS DE INFORMAÇÃO ENQUANTO AGENTES PRESCRITIVOS: COMO "NAVEGAR" NO SISTEMA?}

Um importante evento que também marca esta reconfiguração do modelo de regulação estatal da ciência é a criação da Plataforma Lattes pelo CNPq, em 1999. "Batizada" com esse nome em homenagem ao físico brasileiro César Lattes (1924-2005), a Plataforma Lattes é o mais importante banco de currículos de pesquisadores do país e hoje conta com mais de seis milhões de currículos cadastrados, reunindo informações de todos os núcleos e instituições de pesquisa em atividade no país. ${ }^{7} \mathrm{O}$ banco de dados é utilizado por agências de fomento, universidades e instituições de pesquisa nos seus processos avaliativos, já que representa uma importan-

7 Disponível em: https://www.nexojornal.com.br/expresso/2019/02/27/Quem-foi-C\%C3\%A9sar-Lattes.-E-a-plataforma-que-leva-seu-nome. Acesso em: 14 jul. 2021. 
te ferramenta de acesso rápido à produção científica dos candidatos a editais de financiamento.

A partir da criação da Plataforma Lattes, que sofreu algumas reformulações ao longo dos últimos anos, a inserção na pesquisa científica através da concessão de bolsas e fomentos pelas agências financiadoras passou a ser condicionada ao registro periódico da formação acadêmica e das atividades científicas desempenhadas pelos pesquisadores no banco de dados acessado pelo site do CNPq através de login e senha. A nova ferramenta possibilitou, assim, uma prescrição de modelo curricular acadêmico, tornando mais ágeis as avaliações das agências de fomento e funcionando como um aparato padronizador e classificador dos pesquisadores.

Em 2014, a Capes passou a dispor de uma base de dados para coletar, armazenar e publicar informações dos programas de pós-graduação, a Plataforma Sucupira ${ }^{8}$, cujo preenchimento dos dados é realizado pelos coordenadores desses programas. Com essa nova ferramenta, é possível acessar as páginas de cada área do conhecimento, que contém os documentos de área - nos quais estão descritos o estado atual e as características da área, assim como os critérios considerados prioritários para a classificação do Qualis e para a avaliação dos programas - e os relatórios das avaliações periódicas. ${ }^{9}$

Com base na análise de alguns documentos de área da Capes, traçamos um pequeno esboço das semelhanças e diferenças entre os parâmetros avaliativos de algumas áreas para refletir sobre o modo como pesquisadores que atuam ou atuaram nestes comitês de avaliação foram se conformando e se adaptando a critérios considerados centrais pela agência, como a inserção internacional e a produção intelectual. Um dos parâmetros cobrados pela agência para todas as áreas é que os programas elegíveis aos níveis 6 e 7 desenvolvam produção científica com inserção internacional através de convênios e intercâmbios, colaborações, promoção de eventos científicos internacionais, além da participação docente em comitês editoriais ou como pareceristas em periódicos internacionais.

O aspecto geral que marca a avaliação das áreas de Ciências da Vida e de Ciências Exatas é a centralidade da publicação sob forma de artigo científico e o cálculo de seu fator de impacto, apenas considerando como qualificados nos estratos do Qualis Periódicos as revistas indexadas nas plataformas Web of Science e Scopus, além das disponíveis na base Scielo. Segundo o relatório da avaliação quadrienal de 2017 da área de Física e Astronomia cerca de 20\% dos periódicos estão classificados nos estratos mais altos do Qualis (A1 e A2), sendo que essa

8 A escolha do nome da Plataforma é uma homenagem ao professor Newton Sucupira, autor do Parecer $\mathrm{n}^{\circ}$ 977, de 1965. Disponível em: http://portal.mec.gov.br/component/tags/tag/35995. Acesso em: 14 jul. 2021.

9 Desde 2013, a avaliação deixou de ser trienal e passou a ser realizada por quadriênio. 
minoria concentra mais de $50 \%$ das publicações dos docentes dos programas ${ }^{10}$, confirmando a cobrança por publicações com altos fatores de impacto como condição para o credenciamento e permanência em programas de pós-graduação. O relatório classifica a área de Física e Astronomia como "altamente internacional" desde "sua origem", destacando o fato de seus primeiros doutores terem sido formados no exterior e os veículos de publicação da área serem quase todos internacionais e escritos em língua inglesa.

Em contrapartida, a produção em livro e sua avaliação qualitativa são consideradas de absoluta relevância para as áreas de Humanidades, havendo esforço no refinamento dos critérios de avaliação e classificação das obras através do Qualis Livros ${ }^{11}$. Também é importante destacar que há uma grande quantidade de periódicos considerados importantes no domínio das Ciências Humanas e Sociais que não contam com indicadores de impacto, sendo necessárias formas alternativas de classificá-los e avaliar a produção bibliográfica dos programas. Na área de Sociologia, por exemplo, a estratificação dos periódicos tem como critérios a proporção de autores externos à instituição responsável pela edição (de modo a evitar o que alguns interlocutores classificam pejorativamente como "endogenia acadêmica") e a inserção em mais de um indexador bibliográfico que afira sua qualidade, para além das bases indexadoras que são referência nas áreas de Ciências da Vida e de Ciências Exatas, como Web of Science e Scopus.

A cobrança da Capes por inserção internacional sob forma de produção bibliográfica é vista como problemática por quase todos os interlocutores entrevistados das áreas de Ciências Sociais e Humanidades. Um dos problemas apontados para essa "adequação" da área às exigências da Capes por "internacionalização" é a dificuldade de tradução para a língua inglesa das teorias, conceitos e abordagens trabalhadas nos textos em língua portuguesa da área. Associado a isso, haveria "desinteresse" das revistas internacionais com altos fatores de impacto, escritas em língua inglesa, pelos problemas e linhas abordadas pelos pesquisadores brasileiros, que estariam em grande parte concentradas em temáticas nacionais ou "locais". Tais questões explicariam o baixo número de publicações nacionais indexadas das áreas de Humanidades, se comparado à quantidade de títulos existentes no país - sendo boa parte deles oriundos dos próprios programas de pós-graduação. Sendo justamente nesses títulos nacionais que está concentrada a maior parte dos artigos de pesquisadores brasileiros, os comitês destas áreas baseiam

10 Disponível em: https://www.gov.br/capes/pt-br/acesso-a-informacao/acoes-e-programas/avaliacao/sobre-a-avaliacao/areas-avaliacao/sobre-as-areas-de-avaliacao/colegio-de-ciencias-exatas-tecnologicas-e-multidisciplinar/ ciencias-exatas-e-da-terra/astronomia-fisica. Acesso em: 14 jul. 2021.

11 A inclusão de uma avaliação mais sistemática de livros e da produção artística dos programas ocorreu na avaliação trienal de 2010. 
suas avaliações em parâmetros alternativos aos indicadores de produtividade das bases de dados internacionais.

Um aspecto que aqui nos interessa é entender como os pesquisadores, especialmente os que atuam ou atuaram nos comitês de área da Capes, enxergam essas mudanças nos processos avaliativos dos programas de pós-graduação e de que modo eles conformaram, adaptaram e se apropriaram criativamente desses espaços decisórios. O material de pesquisa aponta para um maior desconforto a este modelo de avaliação da agência por parte dos pesquisadores das Ciências Humanas e Sociais, que afirmam serem induzidos a produzir e avaliar de acordo com parâmetros "estranhos" às suas áreas. Neste sentido, uma estratégia de "fortalecimento" dessas áreas na Capes para enfrentar a "hegemonia avaliativa" das Ciências Biológicas e Exatas, é a mobilização e organização desses pesquisadores através de fóruns de coordenadores de programas de pós-graduação para a realização de consultas entre os pares e a deliberação acerca da representação dessas áreas na Capes. Sobre isso, é representativa a fala de uma pesquisadora da área de Educação que compôs o comitê de área da Capes por alguns anos:

Essa coisa dos fóruns é comum na área de Humanas ou que tenha menos
representatividade pra definir critérios que sejam específicos da área. O que se
objetiva fazer não é aprovar o que é ruim, mas manter uma especificidade da
área. [...] Porque a hegemonia é das áreas médicas, biomédicas. Criou-se uma
hegemonização da ideia de que você tem que ter uma medida razoavelmente
comum. Foi importado o Qualis, indexador que está agindo na vida de todo
mundo, pra mim um absurdo absolutamente completo. O que fazem as
áreas de Exatas? Eles têm fatores de impacto calculados por indexadores
internacionais. Eles pegam os fatores de impacto e avaliam pelos fatores de
impacto. Pega um ponto de corte... "daqui pra cima é A1, daqui pra cima é A2,
daqui pra cima é B1" e está resolvido. Nas áreas Humanas, se a gente fizer
isso, a gente morre, porque não tem índice de impacto. (Fátima, 2017).

Outra questão digna de nota abordada na fala da pesquisadora são as disputas político-epistemológicas (BOURDIEU, 1976) ocorridas no âmbito dos comitês de área das agências de fomento, que tem como ponto central os critérios considerados adequados de avaliação de determinadas áreas e, sobretudo, o que pode ser definido como uma "área" ou campo de pesquisa com legitimidade entre os pares e o corpo técnico da agência para dispor de um comitê próprio, com uma avaliação independente.

Assim como Fátima, outros pesquisadores questionam a autonomia dos comitês de área por considerarem assimétrico o diálogo entre o órgão colegiado e o corpo técnico-burocrático da agência. Essa assimetria, segundo esses atores, é ampliada pela "imposição" de outra lógica de avaliação que "constrange" o trabalho de seus pares nesses comitês, por não corresponder, 
conforme mencionado, às especificidades de pesquisa de suas áreas. No depoimento abaixo, Cícero, pesquisador que atuou no comitê de área de Antropologia/Arqueologia na primeira década de 2000, relativiza criticamente a autonomia do comitê, apontando que o poder decisório dos pares foi diminuindo à medida que foram sendo introduzidos e consolidados os novos parâmetros avaliativos da Capes no fim da década de 1990:

\begin{abstract}
A Capes não tinha o poder que tem hoje sobre a coordenação de área naquele momento. A ideia de representação de área era, de fato, esse mantra 'a Capes somos nós', e era muito mais presente. Nós fazíamos uma leitura qualitativa, né? Porque naquele período, para a nossa área, era possível fazer uma leitura qualitativa. $\mathrm{O}$ documento de área supostamente expressa os valores da área. Hoje isso é muito pouco verdade. A margem que a gente pode ter de leitura do material está balizada por alguma coisa que é estabelecida e chancelada, não é apenas estabelecida pela área hoje em dia. Nossa autonomia é uma autonomia relativa, e muito relativa. Acho que tem uma mudança ao longo do tempo e você tem uma tendência à cristalização. Às vezes as pessoas acreditam demais naquele negócio ali, e levam tempo pra ter senso crítico. Vou lhe contar uma história também, eu acho que os caras das "hard" e biomédicas estão mais confortáveis porque o mar está para eles. A coisa foi formatada de modo propício a eles, esse que é o lance. É por isso que eles se sentem dentro de casa, porque a casa é deles, não é nossa. (Cícero, 2018).
\end{abstract}

Depois de nos debruçarmos sobre os critérios de avaliação, classificação e qualificação do conhecimento científico, tomando de empréstimo os dispositivos presentes no interior das agências de fomento e como são operados pelos cientistas, avançaremos em outras direções para problematizarmos esses processos de difusão da governança pela norma científica e da microfísica da norma. Nesse sentido, um outro universo empírico nos parece pertinente de ser analisado, pois ele amplia nossas lentes de alcance sobre tais fenômenos e suas repercussões sobre o fazer científico. Para tanto, abordaremos o mundo da ética em pesquisa.

\title{
A CONFORMAÇÃO DA REGULAÇÃO DA ÉTICA EM PESQUISA: PARA UMA COMPREENSÃO DA PLATAFORMA BRASIL ${ }^{12}$
}

12 A etnografia apresentada é fruto de pesquisa realizada entre 2016 e 2018 por meio da participação de reuniões
mensais realizadas em um Comitê de Ética em Pesquisa na área de Ciências Humanas e Sociais de uma universida-
de do Rio de Janeiro e do processo de abertura de um CEP da mesma área em outra universidade fluminense. Nela
também analisamos documentos confeccionados pelo Fórum de Ciências Humanas, Sociais e Sociais Aplicadas
(FCHSSA), Grupo de Trabalho - CHS - responsável pela elaboração da Resolução CNS $n^{\circ}$ 510/2016 - e CONEP. 
Para esclarecermos como ocorreu o processo de padronização do controle ético das pesquisas científicas por meio do uso da Plataforma Brasil, antes, é preciso descrever como ele se constitui e quais gramáticas morais estão presentes no sistema de regulação brasileiro da ética em pesquisa, denominado de Sistema CEP/CONEP. Ao explicitarmos esse processo, lançaremos luz sobre como se configura localmente essa governança pelas normas, aliando-se, dessa maneira, às características locais segundo as moralidades presentes em dada instituição.

A regulação da ética em pesquisa no Brasil é realizada pela CONEP no âmbito do Conselho Nacional de Saúde (CNS), que integra o Ministério da Saúde como um conselho de "controle social" ${ }^{13}$. O CNS é composto por 18 comissões, entre elas, a CONEP, e elas visam a "formulação de estratégia e controle da execução de políticas públicas de saúde"14. A CONEP é composta por médicos, bioeticistas, especialistas em saúde coletiva, "representantes de usuários" $" 15$ e das Ciências Humanas e Sociais. Seu colegiado conta com, além de 22 membros titulares e cinco suplentes eleitos dentre os candidatos indicados pelos comitês, oito membros do CNS/Secretaria de Ciência, Tecnologia e Insumos Estratégicos (SCTIE).

A institucionalização de órgãos e regras da prática da pesquisa que envolvem seres humanos no Brasil e em outros países esteve, em primeiro lugar, ligada à área da biomedicina (FASSIN, 2006; FONSECA, 2010; JACOB; RILES, 2006). Preocupações decorrentes das experiências médicas realizadas pelos alemães nazistas e japoneses na Segunda Guerra Mundial motivaram a criação do Código de Nuremberg em 1947 e a declaração dos Direitos dos Homens em 1948, que tinham como intuito regular e normatizar a prática científica, e com isso, definir os princípios éticos da pesquisa médica. Essas ações constituem as primeiras tentativas de regulamentação realizadas pela comunidade científica no que tange à pesquisa em seres humanos, e é daí que advém a locução "ética em pesquisa".

Também foram realizadas entrevistas com membros do CEP e pesquisadores da área de Medicina, e, do mesmo modo, participamos de eventos promovidos pela Academia Nacional de Medicina e pela CONEP.

13 Um dos objetivos do CNS é "fiscalizar, acompanhar e monitorar as políticas públicas de saúde nas suas mais diferentes áreas, levando as demandas da população ao poder público, por isso é chamado de controle social na saúde" (CNS, S/A). O "controle social", nos termos do CNS, diz respeito ao controle do Estado pela sociedade, e não o contrário, como geralmente é utilizado. Disponível em: http://conselho.saude.gov.br/apresentacao/estrutura_organizacional.htm. Acesso em: 02 maio 2021.

14 Disponível em: http://www.conselho.saude.gov.br/apresentacao/apresentacao.htm. Acesso em: 02 maio 2021.

15 O "representante de usuário" integra o colegiado da CONEP e dos Comitês de Ética em Pesquisa, pode ser participante de sociedades e associações de usuários do Sistema Único de Saúde (SUS), devendo ser capaz de "[...] expressar pontos de vista e interesses de indivíduos e/ou grupos sujeitos de pesquisas de determinada instituição e que sejam representativos de interesses coletivos e públicos diversos" (RESOLUÇÃO CNS nº 240/1997). Ele materializa o controle social, pois é através dele que a sociedade não científica, chamada de "leiga", observa os cuidados éticos nos processos avaliativos dessas entidades. 
A primeira versão da Declaração de Helsinque (1964) também constitui um evento importante no processo desse tipo de regulação, influenciando diretamente a criação dos comitês, uma vez que preconizava comissões especiais para o debate da ética em pesquisa. Essa declaração teve um reconhecimento mais amplo que o Código de Nuremberg, pois aparentemente foi formulado para julgar os crimes médicos nazistas, ao passo que a Declaração de Helsinque "[...] projetou-se para o futuro como um guia ético obrigatório para todos os pesquisadores" (DINIZ; CORRÊA, 2001, p. 681), estabelecendo, assim, uma perspectiva universal e universalizante.

Desse modo, baseando-se no Código de Nuremberg, na Declaração dos Direitos do Homem, na Declaração de Helsinque e em diversos outros tratados internacionais, e mobilizações de movimentos organizados da sociedade civil, o CNS, vinculado ao Ministério da Saúde, cria em 1996 a primeira resolução formal que regulamenta as pesquisas em seres humanos no Brasil para controlar danos e riscos individuais causados pela prática da pesquisa médica. A Resolução CNS n¹96/1996 dá origem ao sistema CEP/CONEP, caracterizada entre membros de CEP, principalmente na área da saúde, como um marco histórico no tocante a esse tipo regulação envolvendo seres humanos no Brasil ${ }^{16}$.

Os valores presentes nos tratados acima referidos que serviram como base para o debate sobre ética no Brasil são fortemente marcados pela bioética principialista (DUARTE, 2015; RIBEIRO, 2004). Esta pode ser definida como um campo de saber de informação e controle destinado à discussão das consequências éticas da pesquisa biomédica e se localiza na fronteira da filosofia e da biomedicina e se institucionalizou com a Declaração de Helsinque. As experiências médicas ocorridas em outros países e, notadamente nos Estados Unidos, também foram fundamentais para a consolidação da bioética principialista e desse tipo regulação, especialmente com a publicização do caso de Tuskegee ${ }^{17}$.

A bioética principialista tem seu surgimento referenciado à publicação de Princípios de Ética Biomédica de Beauchamp e Childress, de fins da década de 70, que incorporou os valores presentes no Relatório Belmont ${ }^{18}$ - autonomia, não maleficência, beneficência, justiça

16 Antes deste documento, houve ainda a Resolução CNS nº 01/88, que teve como um dos objetivos criar o grupo de trabalho responsável pela formulação do sistema CEP/CONEP.

17 Entre os anos de 1932 e 1970 foi conduzido um estudo médico sobre o desenvolvimento da sífilis. As pessoas que participaram não foram informadas sobre o objetivo ou o andamento da experiência e eram, em sua grande maioria, constituídas por negros. Eventos que participamos sobre esse tema, quando palestrantes narravam o nascimento dessa ética, mencionavam pesquisas de má conduta científica de repercussão, tais como esse caso de Tuskegee, Willowbrook, células HeLa e entre outros.

18 Em resposta a pesquisas clínicas realizadas nos Estados Unidos, tal como o caso de Tuskegee, o governo e o congresso norte-americano constituíram, em 1974, a National Commission for the Protection of Human Subjects of Biomedical and Behavioral Research, que teve como objetivo principal identificar os princípios éticos que 
e equidade -, aprofundando-os e aplicando-os à pesquisa clínica e assistencial. Nesse sentido, esses princípios são baseados em valores morais de referência estadunidense, marcados por um individualismo liberal anglo-saxão (DINIZ; GUILHEM, 2005) ${ }^{19}$, o que possibilitou sua universalização. O indivíduo representado nessa perspectiva não se encontra no mundo real, pois “[...] é um sujeito livre das hierarquias e de todas as formas de opressão social” (p. 52). A bioética principialista também forneceu um sistema classificatório comum para reflexões mais abrangentes, um modelo para o exercício de uma ética.

A Resolução CNS nº 196/1996 começou a delinear prescrições quanto à obrigatoriedade da avaliação de projetos de pesquisa da área de Ciências Humanas e Sociais pelo Sistema CEP/ CONEP, devido à formulação que inicia o documento, que inclui todas as áreas científicas. O enunciado afirma que a resolução tem a finalidade de "[...] aprovar as seguintes diretrizes e normas regulamentadoras de pesquisas envolvendo seres humanos" (BRASIL, 1996, online, grifo nosso), e um pouco mais abaixo, define o que podem ser os tipos de pesquisa, “[...] pesquisa envolvendo seres humanos - pesquisa que, individual ou coletivamente, envolva o ser humano, de forma direta ou indireta, em sua totalidade ou partes dele, incluindo o manejo de informações ou materiais" (on-line). Já no item II.2, está escrito: "todo procedimento de qualquer natureza envolvendo o ser humano [...] será considerado como pesquisa e, portanto, deverá obedecer às diretrizes da presente Resolução (on-line $)^{20}$.

Órgãos de fomento, instituições que serviriam como lócus para o trabalho de campo e algumas revistas científicas passaram a exigir ${ }^{21}$ a avaliação das pesquisas pelos CEP, principalmente para as áreas de educação, psicologia e serviço social ${ }^{22}$. Nesse primeiro momento, na antropologia, a resolução teve repercussão nas pesquisas direcionadas às instituições de saúde e às sociedades indígenas.

deveriam conduzir a experimentação em seres humanos, ainda hoje considerado um marco histórico e normativo para a bioética principialista.

19 Esta bioética tem recebido diversas críticas, principalmente da chamada bioética latino-americana, formulada de acordo com os contextos locais.

20 Disponível em: https://bvsms.saude.gov.br/bvs/saudelegis/cns/1996/res0196_10_10_1996.html. Acesso em: 19 jan. 2021.

$21 \mathrm{O}$ item XII.2 prescreve que "as agências de fomento à pesquisa e o corpo editorial das revistas científicas deverão exigir documentação comprobatória de aprovação do projeto pelo Sistema CEP/CONEP”, esse foi um dos principais problemas percebidos pelos pesquisadores das Ciências Humanas e Sociais. Disponível em: https:// bvsms.saude.gov.br/bvs/saudelegis/cns/1996/res0196_10 10 1996.html. Acesso em: 19 jan. 2021

22 Estas são as áreas das chamadas Ciências Humanas e Sociais que mais submetem projetos à Plataforma Brasil, observado no relatório do CEP-CFCH e em minha participação no CEP-Humanas, bem como em entrevistas com membros de diferentes comitês. 
Diante disso, em resposta a essa normatização, pesquisadores e associações dessa área começaram a se mobilizar e, entre 2004 e 2015, acionaram diferentes meios na comunidade acadêmica para se manifestar a favor de uma avaliação tida como "justa", confeccionando abaixo-assinados, moções, cartas repúdio, dossiês científicos, livros e entre outros. Destacamos que os argumentos utilizados para elaborar a crítica ao sistema de avaliação da ética em pesquisa e denunciá-lo como "injusto" precisam adquirir legitimidade perante o público envolvido na situação de disputa. Nesse caso, essa legitimidade é construída quando o argumento se baseia numa gramática aceitável e generalizável, tal qual a cívica (BOLTANSKI; THÈVENOT, 1991). Produto dessas ações e de um amplo debate, a Resolução CNS n 510/2016 é aprovada, cuja criação havia sido prevista na Resolução CNS n 466/2012 - que substitui a Res. n 196/1996 com poucas alterações e mantém em seu escopo a denominação genérica de pesquisa- e o Grupo de Trabalho responsável para sua construção é instituído em 2013. A “510”, como assim é chamada, é específica para pesquisas na área de Ciências Humanas e Sociais ${ }^{23}$.

\section{A PLATAFORMA BRASIL: OS INSCRITORES DA ÉTICA EM PESQUISA E $O$ SISTEMA DE CLASSIFICAÇÃO}

Junto à criação do Sistema CEP/CONEP em 1996, também foi implementado o Sistema Nacional de Informação sobre Ética em Pesquisa (SISNEP), cuja função era registrar os projetos de pesquisa envolvendo seres humanos submetidos para avaliação. Outro objetivo era integrar os comitês e a CONEP, atribuindo sentido ao que é chamado de sistema. Em 2012, devido às diferentes críticas levadas ao III Encontro Nacional dos Comitês de Ética em Pesquisa (ENCEP) e à reformulação da Resolução CNS no 196/1996, é construída a Plataforma Brasil em uma base diferente do SISNEP, que passa a realizar todo o processo apenas virtualmente e dando maior atenção ao cuidado com os "representantes de usuários", já que antes, mesmo depois do projeto ser submetido, ainda era preciso levar os documentos produzidos ao CEP para avaliação. As críticas ao SISNEP estavam relacionadas à lentidão de todo processo e à falta de clareza nas informações demandadas. Contudo, é reconhecido como um dos primeiros sistemas que conseguiu concretizar as prerrogativas éticas dos códigos internacionais, gerenciando

23 Para melhor compreensão sobre as controvérsias em torno do processo de construção da Resolução CNS n510/2016, ver Falcão (2020). 
e padronizando as informações concedidas. O SISNEP fortaleceu esse controle da produção científica e entre pares, e a Plataforma Brasil continua dando vida a esse sistema, desse modo, é ela que vincula pesquisadores, membros, comitês e CONEP. Hoje, o Sistema CEP/CONEP conta com mais de $850 \mathrm{CEP}$, majoritariamente vinculados às instituições da saúde, como hospitais universitários e secretarias da saúde. Nesse conjunto, há quatro CEP vinculados à área de Ciências Humanas e Sociais, na Universidade de Brasília (UnB), na Universidade Federal do Rio de Janeiro (UFRJ), na Universidade Federal Fluminense (UFF) e na Universidade Estadual de Campinas (Unicamp).

Como salientado por alguns autores (LAMONT, 2012; LATOUR; WOOLGAR, 1997), é de suma importância para a análise de uma instituição ater-nos aos rituais que a conformam e das performances empreendidas pelos atores. Dessa forma, observaremos como os padrões e normas são acionados in situ. Nesse jogo, eles performam a ética, a ciência e a burocracia. A partir de uma situação de campo em um CEP, descrevemos como ocorre a avaliação: quais os critérios utilizados, os acordos e desacordos, as críticas, o papel dos não humanos e os instrumentos de avaliação.

$\mathrm{O}$ "protocolo de pesquisa" é formado por diferentes documentos submetidos à avaliação, sendo assim chamado quando todos os arquivos adentram à Plataforma Brasil, que são: a carta de anuência; o projeto do pesquisador, que pode assumir outra formatação que não a da Plataforma; o cronograma; o orçamento; e a folha de rosto, composta pelos dados do pesquisador, sua universidade de origem e a assinatura do responsável da sua unidade de atuação. Outro documento gerado pela submissão ao preencher os campos da Plataforma é o de "informações básicas", que consiste na tradução do projeto submetido para o vocabulário do Sistema ${ }^{24}$. Há também o Termo de Assentimento Livre e Esclarecido, o TALE, para "participantes de pesquisa" menores de idade ou em situação de vulnerabilidade; e o Registro de Consentimento Livre e Esclarecido, o RCLE, antes chamado de Termo pela Resolução CNS nº466/2012. Com a promulgação e aprovação da Resolução CNS No510/2016, foi modificada a concepção do acordo entre o pesquisador e o "participante de pesquisa", aceitando outras formas de registros de consentimento. Para consolidar uma identidade em consonância com a chamada "510" e contrastivamente com comitês que têm como referência a " 466 " em sua cultura avaliativa, os membros desse CEP demarcavam a diferença com os outros comitês pela adoção verbal desse novo vocabulário construído com a "510", fato sempre evidenciado por parte dos membros.

24 Os campos preenchidos são os seguintes: introdução, resumo, hipótese, objetivo primário ou principal, objetivo secundário, metodologia proposta, critério de exclusão, critério de inclusão, riscos, benefícios, metodologia da análise de dados, desfecho primário, desfecho secundário, tamanho da amostra e a data de recrutamento. 
Como a controvérsia em torno da Resolução CNS n 510/2016 e a resolução de tipificação da pesquisa e acreditação de risco ainda estava em aberto, e continua, devido à não participação do Grupo de Trabalho original que atuou na construção da 510, um interlocutor enfatizou a necessidade do uso de "registro" e não de "termo" para a obtenção de consentimento informado, já que isso foi uma das "difíceis lutas das $\mathrm{CHS}^{25}$ junto à CONEP". Para ele, então, essa adoção seria uma forma de reconhecer esse processo e demarcar uma identidade diferenciando-os dos comitês da área da saúde.

A Plataforma Brasil é vista pelos pesquisadores de Ciências Humanas e Sociais como um ambiente estranho em que é utilizado um sistema classificatório pouco conhecido, assim como discutimos anteriormente em relação ao caso dos sistemas de avaliação dos pesquisadores. Essa linguagem proveniente da pesquisa clínica faz com que cientistas das Ciências Humanas não encontrem uma forma adequada ao vocabulário de seu campo de conhecimento. Numa entrevista com uma socióloga que trabalha com metodologia quantitativa, ela salientou a desconexão da exigência de preenchimento de campos para um pesquisador das Ciências Humanas e Sociais que realiza pesquisa qualitativa, como o "desfecho". Perguntou-nos se saberíamos elaborar algo que coubesse nesse espaço, afirmamos que não fazíamos ideia inicialmente. Como professora de métodos, tentou elaborar uma explicação e chegou à conclusão que seria impossível preenchê-lo a partir de um projeto de antropologia.

Ainda sobre o vocabulário utilizado é interessante descrever um caso da "área temática especial". Uma pesquisadora preencheu erroneamente um campo na plataforma destinado às "áreas temáticas especiais" da CONEP, que regula projetos cujos temas versam sobre genética e reprodução humana e entre outros ${ }^{26}$. Nesses casos, a avaliação é realizada pelo CEP e pela CONEP. Como o projeto tinha o objetivo de entender o impacto da reprodução assistida no laço familiar, a pesquisadora da área de psicologia preencheu o campo de "genética e reprodução humana", classificando-o sob a nomenclatura de área temática especial, devido a esse equívoco, o projeto permaneceu tramitando por mais de cinco meses. Constituindo um equívoco recorrente, a CONEP, em Carta Circular no 172/2017/CONEP/CNS/MS publicada em 20 de abril de 2017, o reconhece e elabora esclarecimentos referentes ao preenchimento da área temática. A CONEP atribui a solução do problema à demora de atualização da Plataforma, que está tentando junto ao DataSUS - entidade que a gere - modificá-la e torná-la mais ágil.

25 Como são chamadas as Ciências Humanas e Sociais pelos interlocutores da pesquisa, em que se pronuncia apenas as iniciais.

26 Entram também nessa classificação pesquisas com novos fármacos, medicamentos e vacinas; novos equipamentos, insumos e dispositivos para a saúde; população indígena, e projetos que envolvam aspectos de biossegurança. 
Manipular a Plataforma Brasil demanda esforço e tempo para aprender, tanto pela necessidade de apropriação da linguagem específica da "ética em pesquisa" e "bioética principalista", como pela organização virtual e visual dela, que dificulta seus usuários a encontrar as informações e os documentos necessários. Sendo a Plataforma Brasil uma inscritora, ela pode ser tomada como um actante (LATOUR, 2001). Muitas vezes, os membros do comitê e o secretário falavam dela como se estivessem falando de uma pessoa, atribuindo-lhe ação, transformando-a em um sujeito: "a plataforma hoje está querendo atrasar a reunião", "a plataforma não coopera". Certa vez, um membro perguntou ao secretário o que significava alguns "protocolos" estarem em vermelho, o que ele respondeu: “os projetos em vermelho são os que estão sem movimentação há mais tempo, na prática não faz diferença nenhuma, na prática é um jeito da plataforma falar: 'oh, vamos movimentar esse projeto"'. A movimentação à qual ele se refere é tanto do pesquisador quanto do Comitê, muitas vezes os pesquisadores demoram para responder às pendências. Esse secretário conhece tão bem o seu instrumento de trabalho, que, em uma reunião quando a plataforma estava inconstante, ele falou brincando que "sente" quando a plataforma vai cair ou travar.

Em um dia de instabilidade da plataforma, uma integrante do comitê perguntou qual o grau de ingerência, de influência política do CEP para propor alteração, torná-la mais "acessível e menos burra". O secretário então responde que "a plataforma é padrão, que é mais voltada para a área de saúde". Falamos que isso fazia parte da demanda em adequá-la às pesquisas em Ciências Humanas e Sociais feita pelo GT de criação da "510" e do Fórum Ciências Humanas, Sociais e Sociais Aplicadas (FCHSSA ${ }^{27}$. Nessa conversa, outro membro pergunta por que ela acha que o sistema é burro, e em sua resposta, elucida a instabilidade, o tempo de duração da permanência no sistema, que é curto e, se ultrapassado, retorna ao login, e emenda: "mas pior que a burrice é a falta de adequação mesmo".

A partir dessa percepção de que a plataforma "fala outra língua", existe uma preocupação de que o comitê fique apenas exercendo o seu papel burocrático. Essa integrante, que atua na área da educação, menciona a vontade de se mobilizar para "encampar essa luta", e o outro membro afirma que eles são os "operadores do sistema" e que por isso devem estar presentes

27 O FCHSSA foi criado com a finalidade de demandar reconhecimento das áreas envolvidas em relação a diferentes políticas científicas e acadêmicas. O que motivou a sua criação foi a "luta" por um sistema de avaliação da ética em pesquisa adequado às especificidades epistemológicas das áreas que dele participam, nascendo junto ao GT de construção da Resolução CNS no 510/2016. Essa associação recebeu uma nova nomenclatura, as recentes notícias adicionaram às siglas Línguas, Letras e Arte, ficando, então, Fórum de Ciências Humanas, Sociais, Sociais Aplicadas, Línguas, Letras e Artes (FCHSSALLA). Disponível em: https://blogfchssa.wordpress.com/ Acesso em: 05 mar. 2021. 
nessa "luta”, pois senão "a gente só fica 'burrocrático', próximo, próximo" "e discutir ética que é bom...". Enfatiza o neologismo "burrocrático", ressaltando que ao exercerem apenas esse papel, a discussão da ética não acontece, crítica elaborada também por outros membros. Essa mesma integrante resumiu sua crítica e não reconhecimento em relação à plataforma, caracterizando-a como uma "uma realidade paralela".

Nesse sentido, membros, secretários de CEP e pesquisador precisam dominar esse sistema de classificação (DURKHEIM; MAUSS, 1999 KANT DE LIMA, 1995). O pesquisador, ao submeter o "protocolo de pesquisa", precisa dominar o vocabulário da Plataforma, que, apesar de estar presente nas resoluções, muitas vezes é desconhecido. Alguns membros afirmam que esse dispositivo serve para ensinar os pesquisadores a submeter projetos, mas não a serem éticos. As resoluções são publicizadas, mas não compreensíveis, constituindo um conhecimento particularizado na prática, pois os membros, o pesquisador e o secretário "aprendem fazendo", constituindo-se um conhecimento prático.

Além da importância do entendimento desse sistema de classificação, compreendendo “a lógica da plataforma”, é preciso criar estratégias para utilizá-la. Em uma entrevista, uma professora narrou uma apresentação que assistiu quando fazia parte de um comitê: "[...] um dos conselhos que ela [a palestrante] dava, era que: 'primeiro faça tudo no Word, para depois você copiar e colar, porque a plataforma cai no meio e você perde tudo [...]'”. E continua,

Compreender a lógica da plataforma e depois distribuir os temas. Sendo que você pode fazer um texto que não cabe naquele campo. Ou o contrário, ela tem, por exemplo, desfecho primário e secundário. Isso é linguagem da epidemiologia. Em uma pesquisa qualitativa, como é a minha, eu sei traduzir isso para fazer o desfecho primário e secundário, porque a minha pesquisa é na área da saúde. (Letícia, 2018, grifo nosso).

Essa fala revela elementos para a compreensão da lógica própria da prática das Ciências da Saúde. Nesse sentido, os pesquisadores de Ciências Humanas e Sociais, além de não se reconhecerem na Plataforma, também fazem parte de uma comunidade de comunicação (OLIVEIRA, 1996) diferente das Ciências da Saúde, por isso não conhecem a linguagem utilizada por ela. Quando já possuem uma experiência anterior, conseguem adquirir competência para "traduzir" seus projetos de acordo com os termos utilizados nela. Nesse sentido, de acordo com Geertz (2013), no interior de uma comunidade de comunicação e entendimento se constrói um saber comum. O senso comum, para o autor, é "um sistema cultural; um corpo de crenças e juízos, com conexões vagas, porém mais fortes que uma simples relação de pensamento inevitavelmente iguais para todos os membros de um grupo que vive em comunidade" (GEERTZ, 
2013, p.16). Os pesquisadores que compartilham o mesmo senso comum calcado na construção de uma pesquisa a partir da metodologia qualitativa partilham também um vocabulário, uma linguagem similar, mesmo que seguindo tradições epistêmicas distintas.

\section{CONSIDERAÇÕES FINAIS}

Esse processo de modelização de dispositivos de avaliação científica tem o objetivo de ensejar condutas e torná-las menos particulares, além de lançar mão de critérios mais isonômicos, que sejam possíveis de analisar as práticas empreendidas por atores e instâncias diversas. Assim, tenta-se estabelecer standards e normas que sejam validadas em diferentes mundos científicos e em distintas condições de sua realização que transbordam as fronteiras nacionais e disciplinares. Esse processo de padronização, por outro lado, cria caminhos estratégicos conduzidos pela atividade crítica e criativa dos atores implicados na política científica. Neste sentido, há uma demanda por reconhecimento por parte dos interlocutores, principalmente aqueles vinculados às Ciências Humanas e Sociais, pois a transposição de modelos de uma área a outra gera um sentimento de desconsideração (CARDOSO DE OLIVEIRA, 2011; FALCÃO, 2020) e uma enorme dissonância entre os critérios estabelecidos pelas agências de controle da ciência e as práticas heterogêneas empreendidas pelos cientistas em seus respectivos campos do conhecimento.

As situações descritas, seja no que se refere à Plataforma Brasil ou aos critérios de validação do trabalho científico, evidenciam o modo como a governança pela norma científica $a$ la brasileira seguem os princípios de julgamento baseados em um entendimento particularizado sobre as regras (KANT DE LIMA, 1995) e os sentidos de justeza em jogo no processo avaliativo. Desse modo, a particularização das regras e a desconsideração das diferenças epistêmicas caminham juntas nessa política do desconhecimento e da desconsideração.

A tentativa de uniformizar os dispositivos de governança científica culmina, nesse contexto, na deformação dos referenciais que guiam as éticas e as epistemologias científicas essencialmente plurais e heterogêneas. A gramática cívica (BOLTANSKI; THÉVENOT, 1991) mobilizada pelos nossos interlocutores, que tem como referência um modelo ocidental de democracia, dá lugar a outras gramáticas: o da numerologia desenfreada que resulta na elaboração de índices, tabelas, impactos etc. que em muitas circunstâncias empobrecem o exercício científico com a introdução de um regime industrial no mundo da inspiração 
(BOLTANSKI; THÉVENOT, 1991); e, igualmente, o imperialismo bioético (DUARTE, 2015) e epistêmico presente na regulação da ética dissemina uma única e restrita via da eticidade, desconsiderando outras formas presentes no fazer científico.

As Plataformas Lattes e Brasil, bem como as normatizações evidenciam a padronização da atividade científica e da avaliação da ética, dando vida a uma "ética burocrática e um espírito do cartorialismo". A rápida proliferação de agentes ou actantes (LATOUR, 2001; 2012) se configura numa rede múltipla e produz efeitos mútuos: criam normas, estimulam comportamentos, engendram moralidades e produzem subjetividades. No lugar de redes, nesse contexto por nós analisado, conformam-se malhas (EILBAUM, 2006; KANT DE LIMA, 1995) que dão vida às dinâmicas de particularização e interpretação própria sobre a norma e o justo. As malhas são tecidas pelos laços de proximidade, pelas alianças, pela personalização e por critérios que enrijecem e encapsulam o julgamento sobre a prática científica.

As plataformas colocam em ação todo esse sistema avaliativo, tal como o fato científico (LATOUR; WOOLGAR, 1997), o qual, para ser construído, precisa de diversas técnicas e instrumentos. Esse processo é chamado de fenômeno-técnica, pois concede ao fato científico uma aparência de ter sido produzido através de uma técnica pura: sem os inscritores, o fato científico, produto da avaliação, não existiria. Para essa produção são necessários diferentes inscritores, entre não humanos e humanos, deixando seus rastros e causando seus efeitos que, através do agir competente e crítico, criam culturas avaliativas pautadas em fazeres científicos diversos.

A passagem por esses diferentes inscritores e sistemas classificatórios produz um sentimento que realça a crença na norma e nesses critérios universalizantes, padronizadores e uniformizantes. No mundo da "ética burocrática e do espírito do cartorialismo", as avaliações, diante de um universo de malhas normativas, incidem sob o ato de consagração que, segundo Bourdieu (2011, p.113), é “[...] um ato misterioso, que obedece a uma lógica semelhante à da magia, tal como descreve Marcel Mauss". No caso da avaliação da ética, bem como da avaliação da produção científica, por meio de seus rankings classificatórios como o Qualis e Bolsa de Produtividade, esses "atos de consagração" realizados pelo Estado possibilitam o sentimento de inscrição às "boas práticas científicas" e de excelência.

$\mathrm{Na}$ contemporaneidade, o desenvolvimento científico pressupõe o exercício da coexistência e da simetria entre os campos científicos, bem como do pluralismo epistemológico que tanto enriquece o conhecimento reflexivo e crítico cada vez mais posto em xeque diante das forças conservadoras e reacionárias que emergem em diferentes cantos do planeta. A construção de dispositivos de controle da produção científica fundamentado nas concepções hierarquizantes e homogeneizantes sobre o fazer científico, como problematizamos, somente reforçam a 
lógica do colonialismo epistemológico (CARDOSO DE OLIVEIRA, 2004) e da cisma, cuja base central é o exercício arbitrário utilizado pelos agentes responsáveis de definir o científico e ético através de recursos próprios de uma racionalidade cismática (MOTA, 2018; 2021). Diferentemente da desconfiança, fundada sob critérios mutáveis e passíveis de serem validados pela empiria e fatos, a cisma pressupõe o trabalho de julgamento que segue as orientações próprias e particulares ao julgador. É este que detém, neste jogo de carteado avaliativo, os recursos simbólicos e materiais para fundar seus julgamentos e estabelecer os parâmetros válidos na mesa de avaliação. Sendo assim, no percurso do jogo, as cartas podem ser mobilizadas, de forma circunstancial, de acordo com a pessoa que figura como participante da jogada.

\section{REFERÊNCIAS}

1. ARRUDA, M. A. N. A nova política de pós-graduação no Brasil. Tempo Social, São Paulo, v. 11, n. 2, p. 219-229,1999. Disponível em: https://www.scielo.br/j/ts/a/ RrNH64YPRYqmTbtk55hCKTv/?lang=pt. Acesso em: 14 jul. 2021.

2. BARATA, R. C. B. Dez coisas que você deveria saber sobre o Qualis. Revista Brasileira de Pós-Graduação, Brasília, v. 13, n. 30, p. 13-40, 2016. Disponível em: https://rbpg. capes.gov.br/index.php/rbpg/article/view/947. Acesso em: 14 jul. 2021.

3. BEAUCHAMP, T.; CHILDRESS, J. Princípios de ética biomédica. 4.ed. São Paulo: Edições Loyola, 2002.

4. BOLTANSKI, L.; THÉVENOT, L. De la justification: les économies de la grandeur. Paris: Gallimard, 1991.

5. BOLTANSKI, L.; CHIAPELLO, È. O novo espírito do capitalismo. São Paulo: Martins Fontes, 2009.

6. BOURDIEU, P. Le champ scientifique. Actes de La Recherche em Sciences Sociales, n. 2/3, jun. 1976, p. 88-104. Disponível em: https://www.persee.fr/doc/arss_03355322_1976_num_2_2_3454. Acesso em: 14 jul. 2021.

7. BOURDIEU, P. A Economia das trocas linguísticas. São Paulo: Edusp, 2011.

8. BRASIL. Resolução $\mathrm{n}^{\circ}$ 196, de 10 de outubro de 1996. Dispõe sobre diretrizes e normas regulamentadoras de pesquisas envolvendo seres humanos. Diário Oficial [da] República Federativa do Brasil, 16 out. 1996. Disponível em: https://bvsms.saude.gov. br/bvs/saudelegis/cns/1996/res0196_10_10_1996.html. Acesso em: 10 jan. 2021.

9. BRASIL. Resolução no 466, de 12 de dezembro de 2012. Dispõe sobre diretrizes e 
normas regulamentadoras de pesquisas envolvendo seres humanos. Diário Oficial [da] República Federativa do Brasil, Brasília, DF, 13 jun. 2013. Disponível em: http:// conselho.saude.gov.br/resolucoes/2012/Reso466.pdf. Acesso em: 10 jan. 2021.

10. BRASIL. Resolução n⿳ 510, de 07 de abril de 2016. Dispõe sobre as normas aplicáveis a pesquisas em Ciências Humanas e Sociais. Diário Oficial [da] República Federativa do Brasil, Brasília, DF, 24 maio 2016. Disponível em: http:/conselho.saude.gov.br/ resolucoes/2016/Reso510.pdf. Acesso em: 10 jan. 2021.

11. CARDOSO DE OLIVEIRA, L. R. Direito legal e insulto moral: dilemas da cidadania no Brasil, Quebec e EUA. Rio de Janeiro: Relume Dumará, São Paulo, 2011.

12. CARDOSO DE OLIVEIRA, L. R. Pesquisa em versus pesquisas com seres humanos. In: VÍCTORA, C.; OLIVEN, R.G.; MACIEL, M. E.; ORO, A. P. (org.). Antropologia e ética: o debate atual no Brasil. Niterói: EdUFF, 2004.

13. CUERVO, G. L. Sociedade das competências: um estudo sobre circuitos de consagração acadêmicos e construção de reputação científica. 2019. 175. f. Orientador: Fabio Reis Mota. Tese (Doutorado em Antropologia) - Universidade Federal Fluminense, Niterói, 2019. Disponível em: http://ppgantropologia.sites.uff.br/?page_id=4247. Acesso em: 19 jun. 2021.

14. DINIZ, D.; CORRÊA, M. Declaração de Helsinki: relativismo e vulnerabilidade. Cadernos de Saúde Pública, v. 17, n. 3, p. 679-688, 2001. Disponível em: https://www. scielo.br/j/csp/a/rt67g9TP5KrDZSqHS6MDc6Q/abstract/?lang=pt. Acesso em: 14 jul. 2021.

15. DINIZ, D.; GUILHEM, D. O que é bioética? São Paulo: Editora Brasiliense, 2005.

16. DURKHEIM, É.; MAUSS, M. Algumas formas primitivas de classificação. In: MAUSS, M. Ensaios de sociologia. 2. ed., São Paulo: Perspectiva, 1999.

17. DUARTE, L. F. D. A ética em pesquisa nas ciências humanas e o imperialismo bioético no Brasil. Revista Brasileira de Sociologia, v. 3, n. 5, p. 31-52, 2015. Disponível em: http://www.sbsociologia.com.br/rbsociologia/index.php/rbs/article/view/149/0 Acesso em: 14 jul. 2021.

18. EILBAUM, L. Quando o peixe morre pela boca: os casos de Polícia na Justiça Federal Argentina na Cidade de Buenos Aires. 2006. 183f. Orientador: Roberto Kant de Lima Dissertação (Mestrado em Antropologia) - Universidade Federal Fluminense, Niterói, 2006. Disponível em: https://br.antropotesis.alterum.info/?p=2990. Acesso em: 19 jun. 2021.

19. FALCÃO, H. G. "Burocracia da ética": uma análise antropológica sobre a regulação da prática da pesquisa científica no Brasil. 2019.217 f. Orientador: Fabio Reis Mota Tese (Doutorado em Antropologia) - Universidade Federal Fluminense, Niterói, 2019. Disponível em: http://ppgantropologia.sites.uff.br/?page_id=4243. Acesso em: 19 jun. 2021. 
20. FALCÃO, H. G. Controvérsia ética e científica: uma análise sobre reconhecimento e desconsideração no processo de construção da Resolução CNS No 510/2016. In: LIMA, M. L. T.; KANT DE LIMA, R. (org.). Entre normas e práticas: os campos do direito e da segurança pública em perspectiva empírica. 1.ed. Rio de Janeiro: Autografia, 2020.

21. FASSIN, D. The End of Ethnography as Collateral Damage of Ethical Regulation? American Ethnologist, v. 33, n. 4, p. 522-524, 2006. Disponível em: https://www.jstor. org/stable/4098882. Acesso em: 19 jun. 2021.

22. FONSECA, C. Que ética? Que ciência? Que sociedade? In: FLEISCHER, S.; SCHUCH, P. (ed.). Ética e regulamentação na pesquisa antropológica. Brasília: Letras Livres; Editora UnB, 2010. p. 39-70.

23. FOUCAULT, M. Vigiar e punir: nascimento da prisão. Petrópolis, Vozes, 1987.

24. FOUCAULT, M. Histoire de la Folie à l'Age Classique. Paris: Gallimard, 1972.

25. FREIRE, L. L. Seguindo Bruno Latour: notas para uma antropologia simétrica. Comum, Rio de Janeiro, v. 11, n. 26, p.46-65, 2006. Disponível em: http://lemetro.ifcs.ufrj.br/ pesquisadores/Leticia\%20de\%20Luna\%20Freire/latour.pdf Acesso em:14/07/2021.

26. GEERTZ, C. O saber local: novos ensaios em antropologia interpretativa. Petrópolis: Vozes, 2013.

27. JACOB, M. A.; RILES, A. The New Bureaucracies of Virtue: Introduction. Political and Legal Anthropology Review, v. 30, n. 2, p. 181-191, 2006. Disponível em: https:// scholarship.law.cornell.edu/facpub/1304/. Acesso em: 19 jun. 2021.

28. KANT DE LIMA, R. A polícia da cidade do Rio de Janeiro: seus dilemas e paradoxos. 2. ed. Rio de Janeiro: Forense, 1995.

29. LAMONT, M. Toward a Comparative Sociology of Valuation and Evaluation. Annual Review of Sociology, v. 38, p. 201-221, 2012.

30. LATOUR, B. Jamais foram modernos: ensaio de antropologia simétrica. Rio de Janeiro: Editora 34, 2001.

31. LATOUR, B.; WOOLGAR, S. A vida de laboratório: a produção dos fatos científicos. Rio de Janeiro: Relume Dumará, 1997.

32. MARTINS, C. B. Balanço: o papel da CAPES na formação do sistema nacional de pósgraduação. In: FERREIRA, M. de M.; MOREIRA, R. da L. (org.). CAPES 50 anos: depoimentos ao CPDOC/FGV. Rio de Janeiro: Fundação Getúlio Vargas; Brasília: CAPES, 2003. p. 294-309.

33. MOTA, F. R. Kategoriia skhizmy v Brazilii iv mire: vzgliad na sovremennoe konstruirovanie politicheskogo v pragmaticheskoi perspektive. Ètnograficeskoe Obozrenie (MOSKVA, 1992), v. 2, p. 05-73, 2021. The Category of "Schism" in Brazil and Elsewhere: A View of Today's Construction of the Political in the Pragmatic 
Perspective. Disponível em: https://ras.jes.su/ethnorev/s086954150014807-7-1-en. Acesso em: 19 jun. 2021.

34. MOTA, F. R. Do indivíduo blasé aos sujeitos cismados: reflexões antropológicas sobre as políticas de reconhecimento na contemporaneidade. Antropolítica: Revista Contemporânea de Antropologia, v. 44, p. 124-148, 2018. Disponível em: https:// periodicos.uff.br/antropolitica/article/view/41959. Acesso em: 14 jul. 2021.

35. OLIVEIRA, R. C. de. O lugar (e em lugar) do método. Idéias: Revista do Instituto de Filosofia e Ciências Humanas da Unicamp, Campinas, São Paulo, v. 1/2, p. 174-178, 1996. Disponível em: http://dan.unb.br/images/doc/Serie190empdf.pdf Acesso em: 14 jul. 2021.

36. OLIVEIRA, L. R. C. de. Pesquisa em versus pesquisas com seres humanos. In: VÍCTORA, C.; OLIVEN, R.G.; MACIEL, M. E.; ORO, A. P. (org.). Antropologia e ética: o debate atual no Brasil. Niterói: EdUFF, 2004.

37. RIBEIRO, G. L. Prefácio. In: VÍCTORA, C.; OLIVEN, R.G.; MACIEL, M. E.; ORO, A. P. (org.). Antropologia e ética: o debate atual no Brasil. Niterói: EdUFF, 2004.

38. SAAVEDRA, G.A.; SOBOTTKA,E.A.Discursos filosóficos do reconhecimento. Civitas, Porto Alegre, v. 9, n. 3, p. 386-401, 2009. Disponível em: https://revistaseletronicas. pucrs.br/ojs/index.php/civitas/article/view/6898. Acesso em: 14 jul. 2021.

39. TAYLOR, C. Argumentos filosóficos. São Paulo: Edições Loyola, 2000.

40. THÉVENOT, L. Ce qui engage: la sociologie des justifications, conventions et engagements, à la rencontre de la norme. La Revue des Droits de l'Homme, n. 16, 2019. Disponível em: http://journals.openedition.org/revdh/6452. Acesso em: 19 jan. 2021.

41. THÉVENOT, L. La acción en plural: una introducción a la sociologia pragmática. Buenos Aires: Siglo Veintiuno Editores, 2016.

42. THÉVENOT, L. Un gouvernement par les normes, Pratiques et politiques des formats d'information. In: CONEIN, B. THÉVENOT, L. (eds.). Cognition et information en société, Paris: Ed. de l'EHESS (Raisons Pratiques 8), 1997, p. 205-241.

\section{Hully Guedes Falcão}

Pós-doutoranda pelo Programa de Pós-graduação em Informação e Comunicação em Saúde da Fundação Oswaldo Cruz. Doutora em Antropologia pelo Programa de Pós-graduação em Antropologia da Universidade Federal Fluminense. ID ORCID: https://orcid.org/0000-00021932-3104. E-mail: hullyfalcao@gmail.com. Colaboração: Pesquisa bibliográfica, pesquisa empírica, análise de dados, redação e revisão. 


\section{Fabio Reis Mota}

Professor Adjunto do Programa de Pós-graduação em Antropologia da Universidade Federal Fluminense. Coordenador do Núcleo Fluminense de Estudos e Pesquisa, pesquisador do Instituto Nacional de Administração de Conflitos. Doutor em Antropologia pelo Programa de Pós-graduação em Antropologia da Universidade Federal Fluminense. ID ORCID: https://orcid. org/0000-0001-7883-8258. E-mail: reismota@gmail.com. Colaboração: Pesquisa bibliográfica, pesquisa empírica, análise de dados, redação e revisão.

\section{Gabriela de Lima Cuervo}

Professora I de Sociologia da Secretaria de Educação do Rio de Janeiro. Doutora emAntropologia pelo Programa de Pós-graduação em Antropologia da Universidade Federal Fluminense. ID ORCID: https://orcid.org/0000-0003-0766-0805. E-mail: bicuervo@gmail.com. Colaboração: Pesquisa bibliográfica, pesquisa empírica, análise de dados, redação e revisão. 